\title{
Rumen function and digestion parameters associated with differences between sheep in methane emissions when fed chaffed lucerne hay
}

\author{
C. S. PINARES-PATIÑO ${ }^{1,3}$, M. J. ULYATT ${ }^{1 *}$, K. R. LASSEY ${ }^{2}$, T. N. BARRY R \\ AND C. W. HOLMES ${ }^{3}$ \\ ${ }^{1}$ AgResearch Limited, Grasslands Research Centre, Tennent Drive, Private Bag 11008, \\ Palmerston North, New Zealand \\ ${ }^{2}$ National Institute of Water and Atmospheric Research Ltd., P.O. Box 14-901, Kilbirnie, \\ Wellington, New Zealand \\ ${ }^{3}$ Institute of Veterinary, Animal and Biomedical Sciences, Massey University, Palmerston North, \\ New Zealand \\ (Revised MS received 25 September 2002)
}

\begin{abstract}
SUMMARY
An indoor experiment involving 10 rumen-cannulated Romney sheep was conducted in May and June 1998 at AgResearch Grasslands, Palmerston North, New Zealand, under restricted feeding conditions, in order to test the hypothesis that animal factors, in particular rumen fractional outflow rate (FOR) and rumen volume, have an influence on the between-sheep variation in methane $\left(\mathrm{CH}_{4}\right)$ emission. Sheep were fed 2-hourly on chaffed lucerne hay. Following an acclimatization period of 21 days, the experiment lasted 16 days. Energy and nitrogen $(\mathrm{N})$ balances were measured on days 1-6. Cr-EDTA marker was continuously infused into the rumen from day 9 to 16, and rumen contents emptied and sampled on days 13 and 16. Particulate and fluid FOR were estimated using feed lignin and Cr-EDTA, respectively. Daily $\mathrm{CH}_{4}$ production was measured by the sulphur hexafluoride tracer technique on days $2,5,6,12$ and 15 of the experiment.

$\mathrm{CH}_{4}$ production (g/day) was positively correlated with the pool size of organic matter $(\mathrm{OM})$ in the rumen (OM pool, g) $(r=0 \cdot 84, P=0 \cdot 002)$, OM intake (OMI, g/day) $(r=0 \cdot 67, P=0 \cdot 04)$, and the rumen fill (g, wet digesta) $(r=0 \cdot 76, P=0 \cdot 01)$. Multiple regression analysis showed that $\mathrm{CH}_{4}$ production was best predicted $\left(R^{2}=0.88\right)$ as a function of OM pool and the molar \% of butyrate; however, OM pool alone accounted for a large proportion $\left(R^{2}=0 \cdot 71\right)$ of the variation in $\mathrm{CH}_{4}$ production.

$\mathrm{CH}_{4}$ yield ( $\%$ gross energy intake, $\% \mathrm{GEI}$ ) was negatively correlated with the particulate FOR $(\% / \mathrm{h})(r=-0 \cdot 75, P=0 \cdot 01)$ and buffering capacity of rumen fluid $(\mathrm{mmol} \mathrm{HCl})(r=-0 \cdot 72, P=0 \cdot 02)$, but positively correlated with the digestibility of cellulose $(r=0.66, P=0.04)$. Multiple regression analysis showed that $\mathrm{CH}_{4}$ yield was best predicted as a function of particulate FOR, OMI $(\mathrm{g} / \mathrm{kg}$ liveweight $\left.{ }^{0.75}\right)$ and the molar $\%$ of butyrate $\left(R^{2}=0 \cdot 88\right)$. Particulate FOR alone explained a large proportion $\left(R^{2}=0.57\right)$ of the variation in $\mathrm{CH}_{4}$ yield. Particulate FOR was negatively correlated with rumen fill $(r=-0.69, P=0.03)$ and digestibility of cellulose $(r=-0 \cdot 65, P=0 \cdot 04)$.

These results suggest that sheep with lower rumen particulate FOR (i.e. longer rumen retention times) had larger rumen fills and higher fibre digestibilities and $\mathrm{CH}_{4}$ yields. If rumen particulate FOR is to be used as a tool for $\mathrm{CH}_{4}$ mitigation, the repeatability of its relationship to $\mathrm{CH}_{4}$ emission must be assessed, preferably under grazing conditions.
\end{abstract}

\footnotetext{
* To whom all correspondence should be addressed. Email: mwu@paradise.net.nz
} 


\section{INTRODUCTION}

The interaction between ruminant animals and rumen microorganisms is clearly symbiotic. The animal provides the microorganisms with a habitat for growth, whilst the microorganisms, in turn, provide the animal with the ability to digest plant cell wall carbohydrates and also provide nutrients such as volatile fatty acids and microbial protein (Hungate 1966). In the rumen fermentation reactions, reduction of carbon dioxide $\left(\mathrm{CO}_{2}\right)$ with hydrogen $\left(\mathrm{H}_{2}\right)$ and formation of methane $\left(\mathrm{CH}_{4}\right)$ by methanogens has a profound effect on the formation of different end-products, the amount of ATP generated and finally the efficiency of rumen microbial yield (van Nevel \& Demeyer 1996). During fermentation, $\mathrm{H}_{2}$ is formed in large amounts, but it does not accumulate because it is immediately used by methanogens (Wolin \& Miller 1989). Thus, $\mathrm{CH}_{4}$ formation may be seen as a major sink into which the $\mathrm{H}_{2}$ from all rumen organisms drains (Demeyer \& van Nevel 1975).

Although the end-products of rumen fermentation, such as $\mathrm{CH}_{4}$, are the result of microbial activity and are influenced by the diet, it is recognized that animal factors such as mastication, salivation and digesta kinetics affect the rate and type of fermentation (Faichney 1993; Mathison et al. 1995; Wilson \& Kennedy 1996; Varga \& Kolver 1997). Thirty seven years ago, Blaxter \& Clapperton (1965) showed that individual sheep fed on a common diet could differ significantly in their $\mathrm{CH}_{4}$ yields and, more recently, Lassey et al. (1997) have reported that about $86 \%$ of the variation in daily $\mathrm{CH}_{4}$ emission of grazing sheep is between-animal. Part of this variation might be genetic in origin, which might provide a tool for $\mathrm{CH}_{4}$ emission control, but this possibility has not been studied.

Studies both with cattle (Hartnell \& Satter 1979; Ørskov et al. 1988) and with sheep (Hodgson \& Thomas 1975; Faichney 1993) have shown consistent between-animal differences in the rate of outflow of rumen digesta. In all these cases, animals with high outflow rates had smaller rumen volumes. Thus, the hypothesis tested in the current study was that betweenanimal differences in factors such as rumen fractional outflow rate and rumen volume have an influence on the between-sheep variation in $\mathrm{CH}_{4}$ emission.

\section{MATERIALS AND METHODS}

Experimental design

An experiment involving 10 rumen-cannulated sheep was conducted in May and June 1998 at AgResearch Grasslands (Palmerston North, New Zealand), under controlled indoor conditions. There was an acclimatization period of 21 days to accustom the animals to the experimental conditions before a 16-day measurement period. Energy and nitrogen $(\mathrm{N})$ balances were measured for a 6-day period (days 1-6), which was followed by a 2-day transition period (nonmeasurement) before an 8-day rumen digesta kinetics period (days 9-16). In this latter period, a chromium salt of ethylenediamine tetra-acetic acid (Cr-EDTA) was continuously infused into the rumen and rumen contents were bailed out on days 13 and 16. Daily methane production ( $\mathrm{g} /$ day) was measured on days 2 , $5,6,12$ and 15 of the experiment.

\section{Animals}

The sheep were of the Romney breed, cryptorchids and aged 22 months. All sheep were fistulated in the rumen and fitted with permanent rubber cannulae (65 mm i.d.; Beruc Equipment Ltd., South Africa). Leakage of rumen contents was minimized by fitting plastisol washers around the cannulae.

The sheep were kept in digestibility crates and housed in a naturally well-ventilated building. Environmental conditions within the building were not measured, but outside mean ( \pm s.D.) daily maximum and minimum temperatures were $15 \cdot 0( \pm 2 \cdot 29)$ and $6 \cdot 8$ $( \pm 3 \cdot 59){ }^{\circ} \mathrm{C}$, respectively, and the relative humidity was $87 \cdot 6( \pm 8 \cdot 26) \%$.

The sheep were weighed at the start and end of the 16-day measurement period and also immediately prior to emptying the rumen contents.

\section{Feed and feeding}

The sheep were fed on chaffed lucerne (Medicago sativa) hay. The total requirement of hay for the whole experiment was estimated prior to the experiment and after chaffing ( $\sim 50 \mathrm{~mm}$ lengths) it was thoroughly mixed and the individuals' daily requirements were weighed and stored in plastic bags until required. Feeding was at a restricted level (1.2 times the maintenance energy requirements). Automatic overhead feeders delivered the day's ration in 12 feeds, at $2 \mathrm{~h}$ intervals. Drinking water was available ad libitum.

\section{Fluid marker infusion procedure}

The fluid-phase marker Cr-EDTA was prepared by the method of Binnerts et al. (1968) and adjusted to $\mathrm{pH}$ 6.7. The infusate, containing $380 \mu \mathrm{g} \mathrm{Cr} / \mathrm{ml}$ was continuously infused via the rumen cannulae for 8 days at a nominal rate of $0.53 \mathrm{ml} / \mathrm{min}$ using a peristaltic pump (PLG-multipurpose pump; Dasaga, Heidelberg, Germany). The actual infusion rate was determined for each sheep.

\section{Sample collection procedures}

\section{Energy and $N$ balances}

Samples of feed on offer were taken prior to the experiment from the feed batch, before the individual 
daily rations were weighed. After pooling and mixing the samples obtained, two subsamples were taken for dry matter $(\mathrm{DM})$ determination $\left(100^{\circ} \mathrm{C}, 48 \mathrm{~h}\right)$. Two other subsamples were stored at $-20^{\circ} \mathrm{C}$ for chemical analysis.

The design of the digestibility crates allowed the automatic separation of faeces and urine. Faeces were collected onto a meshed tray and a steel chute mounted below the tray served to direct urine into buckets containing sufficient $\mathrm{H}_{2} \mathrm{SO}_{4}(1.8 \mathrm{M})$ to decrease the $\mathrm{pH}$ to between $2 \cdot 5$ and $3 \cdot 0$.

The amounts of daily feed refusals and faeces outputs were recorded and subsamples $(10 \%)$ taken for $\mathrm{DM}$ determinations $\left(100{ }^{\circ} \mathrm{C}, 48 \mathrm{~h}\right)$. Other daily subsamples $(10 \%)$ of feed refusals and faeces were stored frozen $\left(-20^{\circ} \mathrm{C}\right)$. After the collection, all frozen subsamples were pooled within animals, mixed thoroughly, re-sampled, then freeze-dried, ground through a $1 \mathrm{~mm}$ mesh sieve (Wiley Mill, USA) and used for analysis.

Daily urine production was recorded and samples $(10 \%)$ were diluted $(1: 3, \mathrm{v} / \mathrm{v})$ with water, subsampled $(10 \%)$ and stored $\left(-20{ }^{\circ} \mathrm{C}\right)$ for later analysis of purine derivatives (PD) on samples pooled within sheep. Other samples of the daily urine production $(10 \%)$ were taken, stored frozen $\left(-20^{\circ} \mathrm{C}\right)$ and later pooled within sheep, freeze-dried and analysed for energy and $\mathrm{N}$ contents.

\section{Sampling of rumen contents}

Sheep reticulo-rumens (hereafter named rumen) were emptied (bailed) on days 13 (morning) and 16 (afternoon). Rumen bailings took place within 30 and $60 \mathrm{~min}$ after the feed delivery $(09.00 \mathrm{~h}$ on day 13 or $15.00 \mathrm{~h}$ on day 16). Rumen contents were weighed, thoroughly mixed, and sampled before being returned to the rumen. The procedure took about $7 \mathrm{~min}$ per animal. Subsamples of digesta were taken for triplicate DM determination $\left(60^{\circ} \mathrm{C}, 72 \mathrm{~h}\right)$. Other subsamples of digesta were taken and managed in the following way: (1) 200 g was used for immediate $\mathrm{pH}$ determination, then stored $\left(-20^{\circ} \mathrm{C}\right)$, freezedried, ground to pass through a $1 \mathrm{~mm}$ sieve and used for chemical analysis, $(2) \sim 100 \mathrm{~g}$ was stored $\left(-20^{\circ} \mathrm{C}\right)$ and later used for particle size determinations, (3) $\sim 100 \mathrm{~g}$ was stored $\left(-20{ }^{\circ} \mathrm{C}\right)$ for later analysis of $\mathrm{Cr}$ concentration, (4) $\sim 100 \mathrm{~g}$ was strained through a nylon bag ( $60 \mu \mathrm{m}$ mesh) and samples taken for analysis of ammonia $\left(\mathrm{NH}_{3}\right)$ and volatile fatty acid (VFA) concentrations, protozoa counting and measurement of buffering capacity.

The rumen fluid samples for $\mathrm{NH}_{3}$ and VFA analysis were acidified, deproteinized and centrifuged immediately after sampling, using procedures described by Domingue et al. (1991). Samples for protozoa counting were prepared according to Odenyo et al. (1997): $4 \mathrm{ml}$ of strained rumen fluid was added to
$16 \mathrm{ml}$ of formal-saline solution $(8 \cdot 1 \mathrm{~g} \mathrm{NaCl}$ and $100 \mathrm{ml}$ formaldehyde $(37 \% \mathrm{w} / \mathrm{v})$ per litre) and kept at $4{ }^{\circ} \mathrm{C}$ until counting.

\section{$\mathrm{CH}_{4}$ production measurement}

The sulphur hexafluoride $\left(\mathrm{SF}_{6}\right)$ tracer technique (Johnson et al. 1994) was used for daily $\mathrm{CH}_{4}$ production (g/day) measurements. This technique involves dosing each animal with a permeation tube containing $\mathrm{SF}_{6}$, which is calibrated to release $1-2 \mathrm{mg}$ of $\mathrm{SF}_{6}$ over $24 \mathrm{~h}$. Exhaled gas is collected continuously from near the nose via a plastic tube attached to a halter and leading to an evacuated PVC yoke. Thus an integrated $24 \mathrm{~h}$ breath-sample is collected from each participating animal and subsequently analysed by gas chromatography for both $\mathrm{CH}_{4}$ and $\mathrm{SF}_{6}$. All the measurements were carried out while sheep were kept in digestibility crates. Crates were placed $2-3 \mathrm{~m}$ from each other within the building. The PVC gas collection yokes were suspended towards the rear of the digestibility crates and a lengthened sample line from the halter to the yoke was closely attached to the animal's back line to prevent chewing.

\section{Laboratory methods}

Samples of feed offered, feed refusals, faeces and urine were analysed for gross energy (GE) content using an adiabatic bomb calorimeter (Gallenkamp Autobomb - Automatic; London, UK) and for total $\mathrm{N}$ by the Kjeldahl method. Organic matter (OM) content of feed on offer, refusals, faeces and rumen contents was determined by ashing in a furnace at $550{ }^{\circ} \mathrm{C}$ for $16 \mathrm{~h}$. Neutral detergent fibre (NDF), acid detergent fibre (ADF) and acid detergent lignin (ADL) contents of feed, feed refusals, faeces and rumen contents were determined according to the methods of Goering \& van Soest (1970). Hemicellulose was calculated as NDF-ADF, whereas cellulose was calculated as ADF-ADL. Chromium concentration in the rumen digesta was analysed using an Inductively Coupled Plasma Emission Spectrometer (ARL 34000) after digestion with concentrate nitric acid.

Urinary purine derivatives (PD), allantoin, xanthine (plus hypoxanthine) and uric acid were respectively determined using the colorimetric, enzymatic and uricase methods of Chen \& Gomes (1992).

The $\mathrm{pH}$ of rumen contents was determined using a 3020 pH Meter (Jenway Ltd., England). VFA concentrations in rumen fluid were determined by gas chromatography (HRGC 5380, Carlo Erba Instruments, Italy) as described by Hoskin et al. (1995). $\mathrm{NH}_{3}$ concentration in rumen fluid was determined by auto analyser (COBAS, FARA, Basel, Switzerland), using commercially available diagnostic kits (Sigma, St. Louis, USA), which are based on the principle of reductive amination by L-glutamate dehydrogenase. 
Buffering capacity of rumen fluid was determined according to the method described by Ding et al. (1997). Hydrochloric acid ( $\mathrm{HCl}, 1 \mathrm{M})$ was added, in quantities of $20 \mu \mathrm{l}$ at a time, to a $20 \mathrm{ml}$ sample of rumen fluid until $\mathrm{pH} 5.5$ was reached. In this $\mathrm{pH}$ range $(\sim 7 \cdot 0-5 \cdot 5)$, buffering capacity was defined as the amount of acid $(\mathrm{mmol} / \mathrm{l})$ required to change the $\mathrm{pH}$ of $1 \mathrm{ml}$ of rumen fluid by 1 unit (Ding et al. 1997).

The particle size distributions in rumen digesta were determined using a wet sieving apparatus (Turner $\&$ Newall Ltd., England) and following the procedure described by Domingue et al. (1991). The sieve sizes (length of side of square hole) used were $4 \cdot 0,2 \cdot 0,1 \cdot 0$, 0.5 and $0.25 \mathrm{~mm}$. Materials retained on the sieves were washed onto weighed filter paper (Whatman No. 21) in a Buchner funnel and dried at $60^{\circ} \mathrm{C}$ to constant weight to determine the dry weight of each particle size fraction. The dry weight of material not retained on the sieves $(<0.25 \mathrm{~mm}$ particles $)$ was determined by difference from the initial sample dry weight and the sum of recovered particulate DM fractions. Results for each fraction (particulate and soluble) were expressed as the $\%$ of the total initial DM in each sample.

For protozoa counting, a $1-\mathrm{ml}$ aliquot of the formalin-treated rumen fluid sample was pipetted with a wide-orifice pipette into a $20 \mathrm{ml}$ beaker containing $9 \mathrm{ml}$ tap water (1:10 dilution). The diluted sample was pipetted into a counting chamber with a wide-orifice pipette. Protozoa were counted at a magnification of $128 \times$. Each sample was counted in triplicate, and each counting involved 15 fields. The total number of protozoa was counted, and the numbers of holotrichs and entodiniomorphs were also recorded. Protozoa counts were expressed per $\mathrm{ml}$ of rumen fluid.

\section{Calculations}

\section{Daily feed intake and $\mathrm{CH}_{4}$ emission}

The mean daily intakes of DM (DMI), OM (OMI) and GE (GEI) measured during the 6-day balance period were assumed to be the same during the rumen digesta kinetics period.

In the study, the absolute daily production of $\mathrm{CH}_{4}$ ( $\mathrm{g} /$ day) is named ' $\mathrm{CH}_{4}$ production', whereas the proportion of the daily GEI ( $\%$ GEI) lost as $\mathrm{CH}_{4}$ energy is named ' $\mathrm{CH}_{4}$ yield'. A broad term, ' $\mathrm{CH}_{4}$ emission', is used here to refer to $\mathrm{CH}_{4}$ production, $\mathrm{CH}_{4}$ yield and $\mathrm{CH}_{4}$ production rate per unit of intake.

\section{Rumen fill and apparent mean retention time $(A M R T)$ in the rumen}

Rumen fill was measured as the weight ( $\mathrm{g}$ ) of the wet digesta per animal upon bailing.

In order to express the DM fractions (g) of the rumen digesta as a proportion of their respective intakes $(\mathrm{g} / \mathrm{h})$, the apparent mean rumen retention time (AMRT, h) (Minson 1966) of these constituents was calculated.

\section{Fractional outflow rate $(F O R)$ and mean retention time (MRT) in the rumen}

Rumen FOR $(\% / h)$, the proportion of a digesta constituent that leaves the rumen per unit time (Faichney 1980), was calculated using the continuous infusion and total sampling procedure of Faichney (1975). Liquid FOR was calculated with reference to the external marker Cr-EDTA, whereas the internal marker ADL was used to calculate particulate FOR (Domingue et al. 1991). No correction for Cr-EDTA absorption from the rumen was made on the assumption that it was less than $<1.7 \%$ of daily dose (Goodall \& Kay 1973) and it was assumed that the faecal output of ADL represented its abomasal flow (Faichney 1980).

The MRT (h) of the liquid and the particulate phases in the rumen were calculated as the reciprocal of their respective FOR (Faichney 1980).

\section{Digesta particle size distribution and modulus of fineness}

The particle size of rumen digesta was expressed both as 'modulus of fineness' and as 'cumulative DM'. Modulus of fineness was calculated according to the procedure described by Poppi et al. (1980). Alternatively, the cumulative proportions ( $\%$ total DM) and pool size of particles $>1 \mathrm{~mm}$ and $<1 \mathrm{~mm}$ in the rumen were calculated. According to Poppi et al. (1980) the critical particle size for clearance from the rumen is about $1.2 \mathrm{~mm}$.

\section{Microbial N supply from the rumen}

Based on urinary PD excretion, the microbial $\mathrm{N}$ supply (g N/day and $\mathrm{g} \mathrm{N} / \mathrm{kg}$ digestible organic matter apparently fermented in the rumen (DOMR)) was calculated according to the procedures described by Chen \& Gomes (1992). Briefly, the total PD excretion (sum of allantoin, uric acid, xanthine and hypoxanthine; $\mathrm{mmol} /$ day) was calculated. Then, based on the daily excretion of PD (and accounting for the endogenous contribution of PD), the amount of microbial purines absorbed ( $\mathrm{mmol} /$ day) was estimated assuming that $84 \%$ of absorbed purines were recovered as PD in urine. Microbial N supply (g N/day) was calculated assuming: (1) the $\mathrm{N}$ content of absorbed purines was $70 \mathrm{mg} / \mathrm{mmol}$, (2) the digestibility of microbial purines was $83 \%$ and (3) the ratio of purine- $\mathrm{N}$ :total $\mathrm{N}$ in mixed rumen microbes was $11 \cdot 6: 100$.

\section{Statistical analysis}

Data for feed intake, energy and $\mathrm{N}$ balances, $\mathrm{CH}_{4}$ emission and for variables derived from the two 
rumen bailings were pooled for each sheep and the mean values and standard deviations (s.D.) calculated.

The between-sheep variation in $\mathrm{CH}_{4}$ emission was calculated by fitting sheep as class in the GLM procedure of SAS (SAS 1985). For this, all the daily $\mathrm{CH}_{4}$ emission values (5 per sheep) were used.

The relationships between the $\mathrm{CH}_{4}$ production or $\mathrm{CH}_{4}$ yield and each measured variable, were assessed by correlation analysis (SAS 1985). In addition, multiple regression analysis of $\mathrm{CH}_{4}$ production or $\mathrm{CH}_{4}$ yield, upon the other variables was carried out using the forward model-selection method of the stepwise procedure of SAS (1985). In order to guard against the selection of too many variables in the multiple regression model, the level of significance for the SLENTRY criteria for the stepwise procedure (SAS $1985)$ was set at $P<0 \cdot 10$. The aim of the multiple regression analysis was to identify the most important variables responsible for between-animal variation in $\mathrm{CH}_{4}$ production or yield. Thus, intake, rumen pool size, AMRT and apparent digestibility of the digesta constituent (e.g. OM, DM) with the highest partial correlation with $\mathrm{CH}_{4}$ production or $\mathrm{CH}_{4}$ yield were included.

In the multiple regression analysis, the variables included in the model-selection procedure were almost the same for $\mathrm{CH}_{4}$ production and $\mathrm{CH}_{4}$ yield. Exceptions were that in the multiple regression analysis of $\mathrm{CH}_{4}$ yield, the variables feed intake per $\mathrm{kg}$ liveweight $^{0.75}\left(\mathrm{LW}^{0 \cdot 75}\right)$, microbial N supply ( $\mathrm{g} / \mathrm{kg}$ DOMR) and AMRT (h) were also included. When not otherwise stated, the number of observations was $10(10$ sheep).

\section{RESULTS}

\section{Feed intake, energy and $N$ balances and rumen digestion characteristics}

The sheep maintained their LW throughout the experiment (mean $( \pm$ s.D.) LWs at the start and end of experiment were $46 \cdot 8( \pm 5 \cdot 35)$ and $46 \cdot 9( \pm 4 \cdot 81) \mathrm{kg}$, respectively). The feed contained (per $\mathrm{kg} \mathrm{DM}), 30 \cdot 2 \mathrm{~g}$ $\mathrm{N}, 423 \mathrm{~g}$ NDF, $359 \mathrm{~g}$ ADF, $73 \mathrm{~g}$ lignin, $94 \mathrm{~g}$ ash and $18.35 \mathrm{MJ}$ of $\mathrm{GE}$ and mean ( \pm S.D.) daily intakes of DM (g), OM (g) and GE (MJ) were $1083( \pm 114 \cdot 5)$, $987( \pm 92 \cdot 3)$ and $19 \cdot 9( \pm 2 \cdot 10)$, respectively. The mean ( \pm s.D.) apparent digestibilities of DM, OM and GE were 0.591 ( $\pm 0 \cdot 0182), 0 \cdot 604( \pm 0 \cdot 0192)$ and 0.567 $( \pm 0 \cdot 0190)$, respectively. The between-sheep coefficient of variation $(\mathrm{CV}=$ S.D. $/$ mean $)$ for feed intake was $10 \%$. The corresponding $\mathrm{CV}$ for the apparent digestibilities was relatively small $(3 \%)$.

Metabolizable and faecal energy represented 45.9 (8.4 MJ ME $/ \mathrm{kg} \mathrm{DM})$ and $43.4 \%$, respectively of the GE intake (Table 1). Energy losses in urine and $\mathrm{CH}_{4}$ were similar to each other. Urinary excretion represented a loss of $67 \cdot 4 \%$ of $\mathrm{N}$ intake (Table 1). A
Table 1. Mean $( \pm$ S.D. $)$ daily balances and partitioning (\% of intake) of energy $(M J)$ and nitrogen $(N, g)$, and microbial $N$ supply from the rumen $(\mathrm{g} /$ day and $\mathrm{g} / \mathrm{kg}$ DOMR)

\begin{tabular}{ccc}
\hline \hline & \multicolumn{2}{c}{ Balance and partitioning } \\
\hline Energy & $\mathrm{MJ} /$ day & $\%$ of intake \\
Intake & $19 \cdot 9 \pm 2 \cdot 10$ & 100 \\
Excretion & & \\
Faeces & $8 \cdot 6 \pm 1 \cdot 11$ & $43 \cdot 3 \pm 1 \cdot 91$ \\
Urine & $1 \cdot 1 \pm 0 \cdot 08$ & $5 \cdot 6 \pm 0 \cdot 33$ \\
$\mathrm{CH}_{4}$ & $1 \cdot 0 \pm 0 \cdot 08$ & $5 \cdot 2 \pm 0 \cdot 51$ \\
Metabolizable & $9 \cdot 1 \pm 1 \cdot 30$ & $45 \cdot 9 \pm 1 \cdot 89$ \\
$\mathrm{~N} \quad \mathrm{~g} /$ day & \\
Intake & $32 \cdot 9 \pm 2 \cdot 88$ & 100 \\
Excretion & $9 \cdot 4 \pm 1 \cdot 10$ & $28 \cdot 5 \pm 1 \cdot 38$ \\
$\quad$ Faeces & $22 \cdot 2 \pm 2 \cdot 68$ & $67 \cdot 4 \pm 3 \cdot 55$ \\
Urine & $1 \cdot 3 \pm 1 \cdot 29$ & $4 \cdot 1 \pm 4 \cdot 20$ \\
Retained & & \\
Microbial N supply & $11 \cdot 5 \pm 2 \cdot 40$ & \\
g/day & $29 \cdot 6 \pm 4 \cdot 92$ & \\
g/kg DOMR* & & \\
\hline \hline
\end{tabular}

* DOMR, digestible organic matter apparently fermented in the rumen, estimated as 0.65 DOMI, digestible OM intake (Chen \& Gomes 1992).

Table 2. Mean ( \pm S.D.) values for rumen fermentation parameters $\left(\mathrm{pH}, \mathrm{NH}_{3}, \mathrm{VFA}\right)$, buffering capacity of rumen fluid and protozoa counts

\begin{tabular}{lr}
\hline \hline & Mean \pm s.D. \\
\hline $\mathrm{pH}$ & $6 \cdot 8 \pm 0 \cdot 06$ \\
$\mathrm{NH}_{3}(\mathrm{mg} / \mathrm{l})$ & $284 \pm 18 \cdot 2$ \\
$\mathrm{VFA}(\mathrm{mmol} / \mathrm{l})$ & $119 \pm 13 \cdot 4$ \\
Acetate $(\mathrm{mol} \%)$ & $68 \cdot 4 \pm 0 \cdot 73$ \\
Propionate $(\mathrm{mol} \%)$ & $19 \cdot 0 \pm 0 \cdot 90$ \\
Butyrate $(\mathrm{mol} \%)$ & $8 \cdot 2 \pm 0 \cdot 30$ \\
Acetate/propionate & $3 \cdot 6 \pm 0 \cdot 24$ \\
Buffering capacity $(\mathrm{mmol} \mathrm{HCl})$ & $39 \cdot 3 \pm 2 \cdot 11$ \\
Protozoa counts $\left(10^{5} / \mathrm{ml}\right)$ & \\
Holotrichs & $0 \cdot 25 \pm 0 \cdot 082$ \\
Entodinomorphs & $4 \cdot 61 \pm 0 \cdot 951$ \\
Total & $4 \cdot 86 \pm 0 \cdot 981$ \\
\hline \hline
\end{tabular}

large variation was observed in the retention of $\mathrm{N}$ (range: -3.8 to $13.6 \%$ of $\mathrm{N}$ intake) and also in microbial $\mathrm{N}$ supply from the rumen $(\mathrm{g} /$ day or $\mathrm{g} / \mathrm{kg}$ DOMR) (Table 1).

Except for protozoa counts, the variations (CV) in rumen $\mathrm{pH}, \mathrm{NH}_{3}$ concentration, concentrations and molar proportions of VFA and buffering capacity of rumen fluid were relatively small (Table 2). Almost $95 \%$ of the protozoal population were entodiniomorphs, these being mostly small Entodinium. 
Table 3. Mean ( \pm s.D.) rumen fill, pool sizes and particle size distribution of rumen digesta

\begin{tabular}{lc}
\hline \hline & Mean \pm s.D. \\
\hline Rumen fill (g, wet digesta) & $4790 \pm 609 \cdot 8$ \\
Rumen pool size (g) & \\
Liquid & $4243 \pm 518 \cdot 8$ \\
Dry matter (DM) & $546 \pm 98 \cdot 6$ \\
Organic matter (OM) & $482 \pm 90 \cdot 2$ \\
Neutral detergent fibre (NDF) & $303 \pm 64 \cdot 7$ \\
Acid detergent fibre (ADF) & $238 \pm 50 \cdot 1$ \\
Hemicellulose & $65 \pm 15 \cdot 9$ \\
Cellulose & $163 \pm 34 \cdot 7$ \\
Lignin & $75 \pm 15 \cdot 0$ \\
Particle size distribution in rumen & \\
Particles > $>00$ mm & \\
pool size (g DM) & $129 \pm 43 \cdot 0$ \\
$\%$ (of total DM pool) & $23 \cdot 2 \pm 5 \cdot 23$ \\
Particles < $1 \cdot 00$ mm & \\
pool size (g DM) & $417 \pm 69 \cdot 2$ \\
$\%$ (of total DM pool) & $76 \cdot 8 \pm 5 \cdot 21$ \\
Modulus of fineness & $2 \cdot 4 \pm 0 \cdot 17$ \\
\hline \hline
\end{tabular}

Table 4. Mean ( \pm S.D.) values for liquid and particulate fractional outflow rates $(F O R)$, liquid and particulate mean retention times (MRT) and apparent mean retention times (AMRT) of some digesta constituents*

\begin{tabular}{lrrr}
\hline \hline & $\begin{array}{c}\text { FOR } \\
(\% / \mathrm{h})\end{array}$ & \multicolumn{1}{c}{$\begin{array}{c}\text { MRT } \\
(\mathrm{h})\end{array}$} & \multicolumn{1}{c}{$\begin{array}{c}\text { AMRT } \\
(\mathrm{h})\end{array}$} \\
\hline Liquid & $13 \cdot 6 \pm 2 \cdot 78$ & $7 \cdot 7 \pm 1 \cdot 47$ & \\
Particulate & $4 \cdot 1 \pm 0 \cdot 80$ & $25 \cdot 4 \pm 4 \cdot 75$ & \\
DM & & & $12 \cdot 4 \pm 1 \cdot 83$ \\
OM & & & $12 \cdot 0 \pm 1 \cdot 78$ \\
NDF & & $16 \cdot 6 \pm 3 \cdot 53$ \\
ADF & & & $15 \cdot 3 \pm 3 \cdot 11$ \\
Hemicellulose & & & $25 \cdot 3 \pm 8 \cdot 22$ \\
Cellulose & & & $13 \cdot 0 \pm 2 \cdot 60$ \\
Lignin & & $24 \cdot 5 \pm 6 \cdot 17$ \\
\hline \hline
\end{tabular}

* For abbreviations refer to Table 3.

The mean rumen fill (Table 3) represented 10.4\% of the LW of the animal. The liquid component of the rumen fill accounted for $88.5 \%$ of the total contents. Particles below $1.0 \mathrm{~mm}$ size accounted for $76.8 \%$ of the rumen DM content and the modulus of fineness of the particles $(>0.25 \mathrm{~mm})$ was 2.4 (Table 3).

The mean liquid FOR from the rumen was $3 \cdot 3$ higher than the mean particulate FOR (Table 4) and the variations $(\mathrm{CV})$ for these variables were $20 \%$. The AMRT values of digesta constituents (Table 4) indicate that hemicellulose and lignin were the most recalcitrant components for rumen clearance.
The mean $( \pm$ S.E. $)$ daily production of $\mathrm{CH}_{4}$ was $18 \cdot 7$ $( \pm 0 \cdot 72)$ g per sheep and it accounted for $5 \cdot 2( \pm 0 \cdot 14) \%$ of $\mathrm{CH}_{4}$ yield ( $\left.\% \mathrm{GEI}\right)$. Variation between sheep represented 70 and $62 \%$ of the total variation in $\mathrm{CH}_{4}$ production and $\mathrm{CH}_{4}$ yield, respectively.

\section{Relationships between $\mathrm{CH}_{4}$ emission and the other rumen digestion variables}

Table 5 shows the coefficients of correlation $(r)$ between $\mathrm{CH}_{4}$ production (g/day) or $\mathrm{CH}_{4}$ yield ( $\% \mathrm{GEI}$ ) and the other measured variables. $\mathrm{CH}_{4}$ production was positively related to $\mathrm{OMI}(\mathrm{g} /$ day; $P=0.04)$, OM pool size in the rumen (OM pool, $\mathrm{g} ; P=0.002)$ and rumen fill $(\mathrm{g} ; P=0 \cdot 01)$. The correlations between $\mathrm{CH}_{4}$ production and urinary $\mathrm{N}$ ( $\%$ of $\mathrm{N}$ intake), microbial $\mathrm{N}$ supply (g/day), and molar proportion of butyrate (Butyrate, mol \%) were positive, but only approached statistical significance $(P \approx 0 \cdot 10)$.

$\mathrm{CH}_{4}$ yield (\% GEI) was negatively related to the particulate FOR $(\% / \mathrm{h} ; P=0.01)$ and buffering capacity of rumen fluid (mmol HCl; $P=0 \cdot 02$ ), but positively related to the AMRT of organic matter (AMRT of OM, $\mathrm{h} ; P=0.03$ ) and the digestibility of cellulose $(P=0 \cdot 04)$. No significant relationships were found between $\mathrm{CH}_{4}$ yield and the apparent digestibility of other dietary constituents.

The results from the multiple regression analysis were as follows.

\section{(a) $\mathrm{CH}_{4}$ production}

From all the variables included, only two variables were selected into the regression model to best explain the variation in $\mathrm{CH}_{4}$ production. The first variable selected was OM pool $(\mathrm{g})$, which explained $71 \%$ of the total variation (Fig. 1). The second variable selected to enter the model was Butyrate (mol \%), which increased the variation explained by the model to $88 \%$. Thus, the multiple regression model to best explain $\mathrm{CH}_{4}$ production is shown by the equation $( \pm$ s.E. $)$

$$
\begin{aligned}
\mathrm{CH}_{4} \text { production }(\mathrm{g} / \text { day }) & \\
= & -14.4+0.02( \pm 0.003) \mathrm{OM} \text { pool }(\mathrm{g}) \\
& +2.91( \pm 0 \cdot 898) \text { Butyrate }(\mathrm{mol} \%) ; \\
R^{2}= & 0.88 ; P=0.0005
\end{aligned}
$$

\section{(b) $\mathrm{CH}_{4}$ yield}

Of all the variables included, three were selected into the regression model to best explain the variation in $\mathrm{CH}_{4}$ yield. The first variable to be selected was the particulate FOR $(\% / \mathrm{h})$ which explained $57 \%$ of the total variation (Fig. 2). The second variable selected was OMI $\left(\mathrm{g} / \mathrm{kg} \mathrm{LW}^{0.75}\right)$, which together with particulate FOR explained $73 \%$ of the variation in $\mathrm{CH}_{4}$ yield. The third and last variable selected to enter the model was Butyrate (mol \%), which together with the 
Table 5. Coefficients of correlation* between the $\mathrm{CH}_{4}$ production ( $\mathrm{g} /$ day) or $\mathrm{CH}_{4}$ yield $(\% \mathrm{GEI})$ and the other measured variables $\dagger$

\begin{tabular}{lcr}
\hline \hline & $\begin{array}{c}\mathrm{CH}_{4} \text { production } \\
(\mathrm{g} / \text { day })\end{array}$ & $\begin{array}{c}\mathrm{CH}_{4} \text { yield } \\
(\% \mathrm{GEI})\end{array}$ \\
\hline OMI (g/day) & $0 \cdot 67$ & \\
Rumen OM pool (g) & 0.84 & \\
Rumen fill (g, wet digesta) & $0 \cdot 76$ & -0.75 \\
Rumen particulate FOR (\%/h) & & -0.72 \\
Buffering capacity (mmol HCl) & & 0.70 \\
AMRT of OM (h) & & 0.66 \\
Digestibility of cellulose & & \\
\hline \hline
\end{tabular}

* For variables: feed intake, rumen pool size, AMRT and apparent digestibility, only the digesta constituent with the highest correlation coefficient was tabulated. Autocorrelated variables (e.g. FOR $v$. MRT) and non-significant $(P>0 \cdot 05)$ correlations were not tabulated.

$\uparrow$ For abbreviations refer to previous tables.

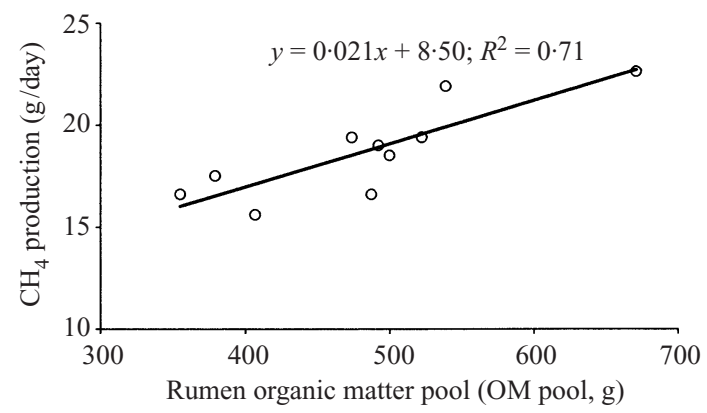

Fig. 1. Relationship between the rumen organic matter pool size (OM pool, g) and daily $\mathrm{CH}_{4}$ production (g/day).

other two variables accounted for $88 \%$ of the variation in $\mathrm{CH}_{4}$ yield. The multiple regression model to best explain the variation in $\mathrm{CH}_{4}$ yield is as shown by the equation $( \pm$ S.E. $)$

$$
\begin{aligned}
\mathrm{CH}_{4} & \text { yield }(\% \mathrm{GEI}) \\
= & 4.21-0.36( \pm 0.08) \text { Particulate FOR }(\% / \mathrm{h}) \\
& -0.03( \pm 0 \cdot 01) \text { OMI }\left(\mathrm{g} / \mathrm{kg} \mathrm{LW}^{0.75}\right) \\
& +0.52( \pm 0 \cdot 20) \text { Butyrate }(\mathrm{mol} \%) \\
R^{2}= & 0.88 ; P=0.004
\end{aligned}
$$

\section{DISCUSSION}

The variation (CV) in the daily feed intake was similar to the variation in LW. Even though sheep were fed at $1 \cdot 2$ times their maintenance requirements, the between-sheep variation (CV) in daily feed intake

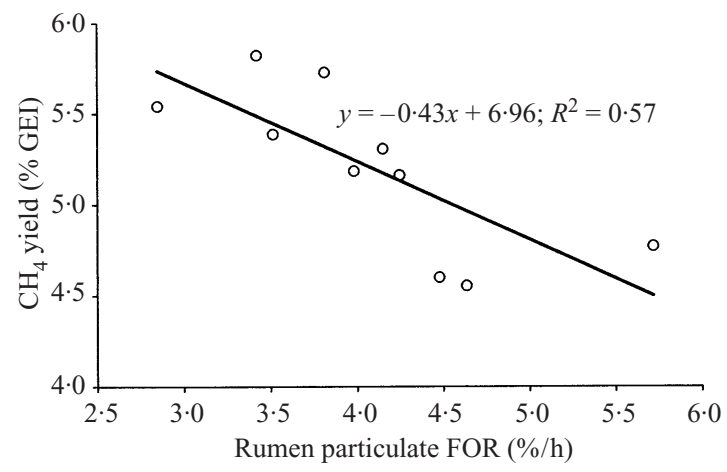

Fig. 2. Relationship between the rumen particulate fractional outflow rate (particulate $\mathrm{FOR}, \% / \mathrm{h}$ ) and daily $\mathrm{CH}_{4}$ yield ( $\%$ GEI).

per $\mathrm{kg} \mathrm{LW}^{0.75}$ was still $7 \%$, a consequence of the differences between-sheep in the ratio of feed DM eaten to that offered, which ranged from 0.88 to 0.98 . Nevertheless, a high correlation $(r=0 \cdot 71, P=0.02)$ was found between the absolute daily feed intake and $\mathrm{LW}^{0.75}$.

In general, the rumen digestion parameters were in the range reported in the literature for sheep fed on lucerne hay (Egan et al. 1975; Ulyatt et al. 1984; Domingue et al. 1991; Nandra et al. 1993; de Vega et al. 1998). The $\mathrm{NH}_{3}$ concentration in the rumen fluid was well above the value of $190 \mathrm{mg} \mathrm{NH}_{3}-\mathrm{N}$, the suggested threshold required for optimal fibre digestion (Mehrez et al. 1977). Nevertheless, two sheep approached a negative $\mathrm{N}$ balance ( $<1 \%$ of $\mathrm{N}$ intake) as a consequence of low feed intake.

The between-sheep variation in daily $\mathrm{CH}_{4}$ production observed in this study is slightly lower than that $(86 \%)$ reported by Lassey et al. (1997) for 50 grazing sheep, but within the range cited by Ulyatt et al. (1999). The restricted and controlled feeding conditions imposed in the present study probably contributed to the lower between-sheep variation in $\mathrm{CH}_{4}$ production. The between-sheep variation in daily $\mathrm{CH}_{4}$ yield observed in this study was $\pm 0.447 \%$ GEI and represented $8.6 \%$ of the mean, a variation $(\mathrm{CV})$ similar to those $(7.2$ and $8.1 \%$ ) reported by Blaxter \& Clapperton (1965) for $\mathrm{CH}_{4}$ measurements carried out in respiration calorimeter chambers.

Methane production was positively and significantly $(P<0.05)$ related to OMI $(\mathrm{g} /$ day $)$, to rumen OM pool (g), and to rumen fill (g) (Table 5). In agreement with the observations of Purser \& Moir (1966), rumen $\mathrm{OM}$ pool was positively related not only to the OMI $(r=0 \cdot 65, P=0 \cdot 04)$, but also to the rumen fill $(r=0.94, P=0.0002)$. These relationships suggest that larger feed intakes were associated with an increased physiological capacity of the rumen, which allowed longer retention times and higher digestion rates 
(Grovum 1984), thus resulting in larger $\mathrm{CH}_{4}$ production.

It is well established (Blaxter \& Clapperton 1965) that $\mathrm{CH}_{4}$ production $(\mathrm{g} /$ day) increases with absolute feed intake and this was confirmed in the present study (Table 5). Nevertheless, in the multiple regression model of $\mathrm{CH}_{4}$ production (Eqn 1), OM pool (g) was identified as being more important than the absolute feed intake (OMI, g/day) and rumen fill. This was possibly due to the restricted feeding level imposed in the study.

Methane production was positively, but not significantly, correlated with urinary $\mathrm{N}(\%$ of $\mathrm{N}$ intake; $r=0 \cdot 60, P=0 \cdot 07)$. It has been shown that the rumen protozoal population contributes positively to $\mathrm{CH}_{4}$ production (Jouany \& Lassalas 2000) and urinary $\mathrm{N}$ loss (Jouany 1995). Nevertheless, no relationship between $\mathrm{CH}_{4}$ production and protozoa count was found in the present study, and urinary $\mathrm{N}$ loss was not selected in the multiple regression model of $\mathrm{CH}_{4}$ production.

Methane production was not related to either the concentrations or molar proportions of acetate or propionate, but it was positively and weakly correlated $(r=0 \cdot 54, P=0 \cdot 10)$ with the molar proportion of butyrate, a relationship which was also reported by Whitelaw et al. (1984). Acetate and butyrate formation in the rumen provide the major sources of $\mathrm{H}_{2}$ for methanogenesis (Wolin 1960) and acetate is considered to be the major precursor of butyrate during rumen fermentation (Russell \& Wallace 1989). In the multiple regression analysis of $\mathrm{CH}_{4}$ production, butyrate $(\mathrm{mol} \%)$ was the second variable selected in the model (Eqn 1) and accounted for $7 \cdot 4 \%$ of the variation in $\mathrm{CH}_{4}$ production. Rumen ciliates have been associated with an increased concentration of butyrate in the rumen fluid (Whitelaw et al. 1984; Hegarty et al. 1994; Jouany \& Lassalas 2000), but no evidence for this was found in the present study. However, it is possible that the straining of rumen digesta through a nylon bag $(60 \mu \mathrm{m}$ mesh) might have excluded some protozoa from the samples of rumen fluid. Butyrate (mol \%) was also selected (ranked third and last) in the multiple regression model of $\mathrm{CH}_{4}$ yield (Eqn 2), explaining an extra $14 \cdot 2 \%$ of the total variation.

Methane yield was positively and significantly $(P<0.05)$ related to AMRT of OM (h) and to the apparent digestibility of cellulose (\%), but negatively and significantly $(P=0 \cdot 01)$ related to the particulate FOR $(\% / \mathrm{h})($ Table 5$)$. These relationships suggest that longer retention times of feed in the rumen were associated with greater digestibility of cell walls and therefore greater $\mathrm{CH}_{4}$ yields. However, from the latter variables, the particulate FOR was identified by the multiple regression analysis as having the strongest relationship to $\mathrm{CH}_{4}$ yield (Eqn 2), explaining 57\% of the total variation (see Fig. 2). The influence of particulate FOR on $\mathrm{CH}_{4}$ yield is in agreement with previous observations (Demeyer \& van Nevel 1975; Okine et al. 1989), i.e. the higher the particulate FOR, the lower the $\mathrm{CH}_{4}$ yield due to the shorter time that feed particles are exposed to microbial fermentation.

Methane yield was negatively correlated $(P=0 \cdot 02)$ with the buffering capacity of rumen fluid (Table 5). In this study, lucerne hay was the sole feed and no between-sheep variation in $\mathrm{pH}$ was observed $(\mathrm{CV}<1 \%)$. Therefore, under these conditions it is unlikely that buffering capacity directly influenced $\mathrm{CH}_{4}$ yield, but probably reflected the relationship between the rumen particulate FOR and $\mathrm{CH}_{4}$ yield. Saliva is an important source of buffer in the rumen system (Ding et al. 1997) and the rate of saliva production influences the rumen dilution rate (Harrison et al. 1975; Sibanda et al. 1997). In the present study, buffering capacity was not correlated to liquid FOR $(r=0 \cdot 26, P=0 \cdot 46)$, but was positively and weakly correlated $(r=0.57, P=0.08)$ to particulate FOR. Buffering capacity was not identified in the multiple regression model of $\mathrm{CH}_{4}$ yield as accounting for more variation than particulate FOR alone.

From the apparent digestibilities of dietary constituents, only the digestibility of cellulose was correlated $(P=0.04)$ with $\mathrm{CH}_{4}$ yield, in agreement with the knowledge that cellulose is the most methanogenic carbohydrate (Moe \& Tyrrell 1979). The positive relationship between the digestibility of cellulose and $\mathrm{CH}_{4}$ yield is in agreement with the observations of Blaxter \& Clapperton (1965) for a restricted feeding level (an effect of longer rumen retention time). However, the digestibility of cellulose was not selected in the multiple regression model of $\mathrm{CH}_{4}$ yield, probably because its effect was overshadowed by that of particulate FOR.

The correlation between the $\mathrm{CH}_{4}$ yield and OMI per $\mathrm{kg}$ of $\mathrm{LW}^{0.75}$ approached significance $(r=-0 \cdot 52$, $P=0 \cdot 12)$. OMI $\left(\mathrm{g} / \mathrm{kg} \mathrm{LW}^{0} \cdot 75\right)$ was the second variable selected to enter the multiple regression model of $\mathrm{CH}_{4}$ yield (Eqn 2), accounting for an extra $16 \%$ of the total variation. $\mathrm{CH}_{4}$ yield decreased as $\mathrm{OMI}(\mathrm{g} / \mathrm{kg}$ $\mathrm{LW}^{0 \cdot 75}$ ) increased, a relationship also observed in other studies (Blaxter \& Clapperton 1965; Pelchen \& Peters 1998).

The quantitative interaction between the fractional rates of digestion and passage determines the digestibility in the rumen (Poppi et al. 2000). In the present study, with restricted feeding, particulate FOR $(\% / \mathrm{h})$ was the major factor involved in the between-sheep variation in $\mathrm{CH}_{4}$ yield. Particulate FOR not only correlated negatively with rumen fill (weight of wet digesta) $(r=-0.69, P=0.03)$, but also with cellulose digestibility $(r=-0 \cdot 65, P=0 \cdot 04)$. Thus, larger rumen fills were associated with longer retention times of feed in the rumen and consequently greater fibre digestibilities and $\mathrm{CH}_{4}$ yields. Whether these interrelationships, observed at restricted feeding conditions, are the same under ad libitum feeding conditions 
(e.g. generous pasture allowance at grazing), is unknown.

In conclusion, although methane is produced by microbes, the study has demonstrated that rumen particulate fractional outflow rate (particulate FOR), an animal factor, explained a large part of the between-sheep variation in $\mathrm{CH}_{4}$ yield. If this relationship was persistent under ad libitum feeding in the long-term and the rumen particulate FOR was heritable, genetic selection might be effective as a tool to reduce livestock $\mathrm{CH}_{4}$ emission.
The authors acknowledge Dr G. C. Waghorn (AgResearch Grasslands) for his assistance and suggestions during the experiment. The skilled assistance of I. D. Shelton (AgResearch Grasslands) and J. Purchas (Massey University) is also acknowledged. C. S. Pinares-Patiño was in receipt of a postgraduate scholarship from the New Zealand Ministry of Foreign Affairs and Trade. This research was funded by the NZ Foundation for Research, Science and Technology and by the NZ Ministry of Agriculture and Fisheries.

\section{REFERENCES}

Binnerts, W. T., van't Klooster, A. T. \& Frens, A. M. (1968). Soluble chromium indicator measured by atomic absorption in digestion experiments. Veterinary Record 82, 470 .

Blaxter, K. L. \& Clapperton, J. L. (1965). Prediction of the amount of methane produced by ruminants. British Journal of Nutrition 19, 511-522.

Chen, X. B. \& Gomes, M. J. (1992). Estimation of Microbial Protein Supply to Sheep and Cattle Based on Urinary Excretion of Purine Derivatives - An Overview of the Technical Details (Occasional Publication). Aberdeen: Feed Resources Unit, The Rowett Research Institute.

Demeyer, D. I. \& van Nevel, C. J. (1975). Methanogenesis, an integrated part of carbohydrate fermentation, and its control. In Digestion and Metabolism in the Ruminant, Proceedings of the 4th International Symposium on Ruminant Physiology (Eds I. W. McDonald \& A. C. I. Warner), pp. 366-382. University of New England, Armidale, Australia: The University of New England Publishing Unit.

de Vega, A., Gasa, J., Castrillo, C. \& Guada, J. A. (1998). Passage through the rumen and the large intestine of sheep estimated from faecal marker excretion curves and slaughter trials. British Journal of Nutrition 80, 381-389.

Ding, Z., Rowe, J. B., Godwin, I. R. \& Xu, Y. (1997). The buffering capacity of caecal digesta exceeds that of rumen digesta from sheep fed pasture or roughage diets. Australian Journal of Agricultural Research 48, 723-728.

Domingue, B. M. F., Dellow, D. W. \& Barry, T. N. (1991). Voluntary intake and rumen digestion of a low quality roughage by goats and sheep. Journal of Agricultural Science, Cambridge 117, 111-120.

Egan, A. R., Walker, D. J., Nader, C. J. \& Storer, G. (1975). Comparative aspects of digestion of four roughages by sheep. Australian Journal of Agricultural Research 26, 909-922.

FAichney, G. J. (1975). The use of markers to partition digestion within the gastro-intestinal tract of ruminants. In Digestion and Metabolism in the Ruminant, Proceedings of the 4th International Symposium on Ruminant Physiology (Eds I. W. McDonald \& A. C. I. Warner), pp. 277-291. University of New England, Armidale, Australia: The University of New England Publishing Unit.

FAichney, G. J. (1980). Measurement in sheep of the quantity and composition of rumen digesta and of the fractional outflow rates of digesta constituents. Australian Journal of Agricultural Research 31, 1129-1137.
FAIChNEY, G. J. (1993). Digesta flow. In Quantitative Aspects of Ruminant Digestion and Metabolism (Eds J. M. Forbes \& J. France), pp. 53-85. Wallingford: CAB International.

Goering, H. K. \& van Soest, P. J. (1970). Forage fiber analysis. Agricultural Handbook 379, 1-20.

Goodall, E. D. \& Kay, R. N. B. (1973). The use of the chromium complex of ethylenediamine tetraacetic acid for studies of digestion in sheep. Proceedings of the Nutrition Society 32, 22A-23A.

Grovum, W. L. (1984). Integration of digestion and digesta kinetics with control of feed intake-a physiological framework for a model of rumen function. In Herbivore Nutrition in the Subtropics and Tropics (Eds F. M. C. Gilchrist \& R. I. Mackie), pp. 244-268. Craighall, SA: The Science Press.

Harrison, D. G., Beever, D. E., Thomson, D. J. \& Osbourn, D. F. (1975). Manipulation of rumen fermentation in sheep by increasing the rate of flow of water from the rumen. Journal of Agricultural Science, Cambridge 85, 93-101.

Hartnell, G. F. \& Satter, L. D. (1979). Determination of rumen fill, retention time and ruminal turnover rates of ingesta at different stages of lactation in dairy cows. Journal of Animal Science 48, 381-392.

Hegarty, R. S., Nolan, J. V. \& Leng, R. A. (1994). The effects of protozoa and of supplementation with nitrogen and sulfur on digestion and microbial metabolism in the rumen of sheep. Australian Journal of Agricultural Research 45, 1215-1227.

Hodgson, J. C. \& Thomas, P. C. (1975). A relationship between the molar proportion of propionic acid and the clearance rate of the liquid phase in the rumen of sheep. British Journal of Nutrition 33, 447-456.

Hoskin, S. O., Stafford, K. J. \& Barry, T. N. (1995). Digestion, rumen fermentation and chewing behaviour of red deer fed fresh chicory and perennial ryegrass. Journal of Agricultural Science, Cambridge 124, 289-295.

Hungate, R. E. (1966). The Rumen and its Microbes. New York: Academic Press.

Johnson, K., Huyler, M., Westberg, H., Lamb, B. \& Zimmerman, P. (1994). Measurements of methane emissions from ruminant livestock using a $\mathrm{SF}_{6}$ tracer technique. Environmental Science and Technology 28, 359-362.

JouANY, J. P. (1995). Effect of rumen protozoa on nitrogen utilization by ruminants. Journal of Nutrition 126, 1335S-1346S. 
Jouany, J. P. \& Lassalas, B. (2000). Effect of protozoa on methane production in the rumen; consequences on carbon and hydrogen distribution among the other end products of fermentation. In Methane Mitigation, Proceedings of Second International Conference, pp. 121-123. Novosibirsk, Russia: U.S. Environmental Protection Agency and Siberian Branch of Russian Academy of Sciences.

Lassey, K. R., Ulyatt, M. J., Martin, R. J., Walker, C. F. \& Shelton, I. D. (1997). Methane emissions measured directly from grazing livestock in New Zealand. Atmospheric Environment 31, 2905-2914.

Mathison, G. W., Okine, E. K., Vaage, A. S., Kaske, M. \& Milligan, L. P. (1995). Current understanding of the contribution of the propulsive activities in the forestomach to the flow of digesta. In Ruminant Physiology: Digestion, Metabolism, Growth and Reproduction, Proceedings of the Eighth International Symposium on Ruminant Physiology (Eds W. V. Engelhardt, S. Leonhard-Marek, G. Breves \& D. Giesecke), pp. 23-41. Stuttgart: Ferdinand Enke Verlag.

Mehrez, A. Z., Ørskov, E. R. \& McDonald, I. (1977). Rates of rumen fermentation in relation to ammonia concentration. British Journal of Nutrition 38, 437-443.

Minson, D. J. (1966). The apparent retention of food in the reticulo-rumen at two levels of feeding by means of an hourly feeding technique. British Journal of Nutrition 20, 765-773.

Moe, P. W. \& Tyrrell, H. F. (1979). Methane production in dairy cows. Journal of Dairy Science 62, 1583-1586.

Nandra, K. S., Hendry, A. \& Dobos, R. C. (1993). A study of voluntary intake and digestibility of roughages in relation to their degradation characteristics and retention time in the rumen. Animal Feed Science and Technology 43, 227-237.

Odenyo, A. A., Osuji, P. O. \& Karanfil, O. (1997). Effect of multipurpose tree (MPT) supplements on ruminal ciliate protozoa. Animal Feed Science and Technology 67, 169-180.

Okine, E. K., Mathison, G. W. \& Hardin, R. T. (1989). Effects of changes in frequency of reticular contractions on fluid and particulate passage rates in cattle. Journal of Animal Science 67, 3388-3396.

Ørskov, E. R., Ojwang, I. \& Reid, G. W. (1988). A study on consistency of differences between cows in rumen outflow rate of fibrous particles and other substrates and consequences for digestibility and intake of roughages. Animal Production 47, 45-51.

Pelchen, A. \& Peters, K. J. (1998). Methane emission from sheep. Small Ruminant Research 27, 137-150.

Poppi, D. P., France, J. \& McLennan, S. R. (2000). Intake, passage and digestibility. In Feeding Systems and Feed
Evaluation Models (Eds M. K. Theodorou \& J. France), pp. 35-52. Wallingford: CAB International.

Poppi, D. P., Norton, B. W., Minson, D. J. \& Hendrickson, R. E. (1980). The validity of the critical size theory for particles leaving the rumen. Journal of Agricultural Science, Cambridge 94, 275-280.

Purser, D. B. \& Moir, R. J. (1966). Rumen volume as a factor involved in individual sheep differences. Journal of Animal Science 25, 509-515.

Russell, J. B. \& Wallace, R. J. (1989). Energy yielding and consuming reactions. In The Rumen Microbial Ecosystem (Eds P. N. Hobson \& R. J. Wallace), pp. 185-216. London: Elsevier Applied Science.

SAS (1985). User's Guide: Statistics, Version 5. Cary, NC: SAS Inst., Inc.

Sibanda, S., Hatendi, P. R., Mulenga, F. M. \& Ndlovu, P. (1997). The effect of diet and frequency of watering on rumen degradability and outflow rate of lowquality veld hay and dry-matter apparent digestibility in steers given food at maintenance. Animal Science $\mathbf{6 5}$, $159-164$.

Ulyatt, M. J., Baker, S. K., McCrabb, G. J. \& Lassey, K. R. (1999). Accuracy of $\mathrm{SF}_{6}$ tracer technology and alternatives for field measurements. Australian Journal of Agricultural Research 50, 1329-1334.

Ulyatt, M. J., Waghorn, G. C., John, A., Reid, C. S. W. \& Monro, J. (1984). Effect of intake and feeding frequency on feeding behaviour and quantitative aspects of digestion in sheep fed chaffed lucerne hay. Journal of Agricultural Science, Cambridge 102, 645-657.

van Nevel, C. J. \& Demeyer, D. I. (1996). Control of rumen methanogenesis. Environmental Monitoring and Assessment 42, 73-97.

Varga, G. A. \& Kolver, E. S. (1997). Microbial and animal limitations to fiber digestion and utilization. Journal of Nutrition 127, 819S-823S.

Whitelaw, F. G., Eadie, J. M., Bruce, L. A. \& Shand, W. J. (1984). Methane formation in faunated and ciliatefree cattle and its relationship with rumen volatile fatty acid proportions. British Journal of Nutrition 52, 261-275.

Wilson, J. R. \& Kennedy, P. M. (1996). Plant and animal constraints to voluntary feed intake associated with fibre characteristics and particle breakdown and passage in ruminants. Australian Journal of Agricultural Research 47, 199-225.

Wolin, M. J. (1960). A theoretical rumen fermentation balance. Journal of Dairy Science 43, 1452-1459.

Wolin, M. J. A. \& Miller, T. L. (1989). Microbe-microbe interactions. In The Rumen Microbial Ecosystem (Eds P. N. Hobson \& R. J. Wallace), pp. 343-359. London: Elsevier Applied Science. 
Rumen function and digestion parameters associated with differences between sheep in methane emissions when fed chaffed lucerne hay

Pinares-Patiño, C. S.

2003

http://hdl.handle.net/10179/9678

22/04/2023 - Downloaded from MASSEY RESEARCH ONLINE 